\title{
CARACTERÍSTICAS FÍSICO-QUÍMICAS E PROPRIEDADES FUNCIONAIS TECNOLÓGICAS DO BAGAÇO DE MIRTILO FERMENTADO E SUAS FARINHAS ${ }^{1}$
}

\author{
BRUNA GOLDMEYER ${ }^{2}$, NEIDI GARCIA PENNA ${ }^{3}$, \\ ÂNGELA MELO ${ }^{4}$, CLAUDIA SEVERO DA ROSA ${ }^{3}$
}

RESUMO - A industrialização de frutas permite que os consumidores usufruam seus benefícios funcionais; porém, na maioria das vezes, o processamento produz resíduos industriais que normalmente não são aproveitados. Desta forma, o bagaço do mirtilo é um subproduto da fermentação que geralmente é desprezado na natureza, originando poluição ambiental. Este trabalho objetivou a caracterização físico-química, a determinação da atividade antioxidante, antocianinas e polifenóis do fruto de mirtilo, bagaço de mirtilo proveniente da produção de bebidas fermentadas e da farinha obtida deste bagaço, bem como as propriedades funcionais tecnológicas e a estabilidade microbiológica destas farinhas. As farinhas do fruto e do bagaço foram obtidas a partir da desidratação em estufa a $60{ }^{\circ} \mathrm{C}$, por $36 \mathrm{~h}$, e moídos em micromoinho refrigerado a $4{ }^{\circ} \mathrm{C}$. As características físico-químicas foram verificadas a partir das análises de umidade, proteína, lipídeos, cinzas, acidez, $\mathrm{pH}$ e sólidos solúveis. A atividade antioxidante foi determinada pelo método DPPH, e os polifenóis totais, pelo método de Folin-Ciocalteu. Os resultados demonstram que tanto o mirtilo quanto o bagaço possuem elevado conteúdo de água. O mirtilo apresentou 61,67 mg/100 g em antocianinas, 431,43 $\mathrm{mg}$ EAG/100 g em polifenóis e $3,83 \mathrm{mg} / \mathrm{mL}$ de atividade antioxidante, enquanto o bagaço obteve 57,32 $\mathrm{mg} / 100 \mathrm{~g} ; 297,20 \mathrm{mg}$ EAG/100 g; 5,61 mg/mL, respectivamente. As farinhas apresentaram estabilidade microbiológica durante o armazenamento e propriedades funcionais tecnológicas adequadas, possibilitando a geração de novos produtos. Portanto, o aproveitamento de resíduos industriais de mirtilo fermentado apresenta vantagens de agregar valor e minimizar o impacto no meio ambiente.

Termos para indexação: atividade antioxidante, antocianina, polifenóis.

\section{PHYSICOCHEMICAL CHARACTERISTICS AND TECHNOLOGICAL FUNCTIONAL PROPERTIES OF FERMENTED BLUEBERRY POMACE AND THEIR FLOURS}

\begin{abstract}
The industrialization of fruit allows consumers to continue enjoying their functional benefits for longer, but most often these procedures produce industrial wastes that are not normally utilized. Therefore this study aimed to physicochemical characterization, determination of antioxidant activity, anthocyanins and polyphenols in blueberry pomace from the production of fermented beverages and flour obtained from this bagasse, as well as the functional properties of technological and microbiological stability of flour. Flours fruit and bagasse were obtained from the dehydration in an oven at $60^{\circ} \mathrm{C}$ for 36 hours and ground into micro mill refrigerated at $4{ }^{\circ} \mathrm{C}$. The physicochemical characteristics were observed from the analyzes of moisture, protein, lipid, ash, acidity, pH and soluble solids. The antioxidant activity was determined by DPPH and total polyphenols by the Folin-Ciocalteu. The results showed that both blueberry, as bagasse, have a high water content. The blueberry showed $61.67 \mathrm{mg} / 100 \mathrm{~g}$ in anthocyanins, polyphenols in EAG/100g $431.43 \mathrm{mg}$ and $3.83 \mathrm{mg} / \mathrm{mL}$ of antioxidant activity, while the bagasse obtained $57.32 \mathrm{mg} / 100 \mathrm{~g}, 297.20 \mathrm{mg}$ EAG/100g, $5.61 \mathrm{mg} / \mathrm{mL}$, respectively. Flours showed microbiological stability during storage and functional properties of very good technology, enabling the creation of new products. Therefore the use of industrial waste has many advantages as add value and minimize environmental impact.
\end{abstract}

Index terms: blueberry, bagasse, flour, anthocyanins, polyphenols

\footnotetext{
(Trabalho 380-13). Recebido em: 08-10-2013. Aceito para publicação em : 07-10-2014.

${ }^{2}$ ecnóloga em Alimentos, UFSM: E-mail: bruna.golda@hotmail.com

${ }^{3}$ Docentes do Departamento de Tecnologia e Ciência dos Alimentos, UFSM: E-mail: ngpenna@gmail.com; claudiasr37@yahoo.com.br

${ }^{4}$ Aluna do curso Superior em Tecnologia dos Alimentos, UFSM: E-mail: angelaarrue@gmail.com
} 


\section{INTRODUÇÃO}

O mirtilo é um fruto pouco conhecido no Brasil, porém com grande potencial produtivo, principalmente no Estado do Rio Grande do Sul, devido ao clima temperado (RASEIRA; ANTUNES, 2004). Também conhecido por blueberry, arándano ou uva-do-monte, é uma fruta da família das Ericaceae e pertence ao grupo de pequenas frutas, como amoras, morangos e framboesas (SOUSA et al., 1995). É originário de algumas regiões da Europa e América do Norte, onde é apreciado por seu sabor exótico, pelo valor econômico e por seus poderes medicinais como "fonte de longevidade", devendose especialmente ao alto conteúdo de antocianinas que são pigmentos de cor azul-púrpura (ANTUNES; MADAIL, 2007). Em particular, o mirtilo contém elevados níveis de antocianinas e compostos fenólicos com grande capacidade antioxidante in vitro, comparado a outros frutos (WANG; JIAO, 2000).

Estas pequenas frutas constituem-se em fontes naturais de substâncias bioativas, com ação antioxidante e anticancerígena, chamando a atenção dos consumidores que buscam melhor qualidade de vida (PANTELIDIS et al., 2007). Particularmente, os polifenóis estão em conteúdo elevado tanto na casca quanto na polpa, os quais conferem funções de proteção sobre as paredes das células. O mirtilo possui grandes benefícios e pode ser consumido tanto in natura como após o processamento por congelamento, desidratação ou enlatamento.

A fabricação de fermentados de mirtilo permite que os consumidores continuem usufruindo seus benefícios funcionais, porém na maioria das vezes estes procedimentos produzem resíduos industriais que normalmente não são aproveitados. Dentre estes resíduos, existe o bagaço do mirtilo que é um subproduto da fermentação e que geralmente é desprezado na natureza. $\mathrm{O}$ mirtilo, por ser um fruto que possui compostos bioativos, deve ser totalmente aproveitado, de modo que o mercado de novos produtos faça uso dos resíduos industriais gerados. Os resíduos da produção de bebidas fermentadas, de maneira geral, são caracterizados por conter altos teores de compostos fenólicos devido à extração insuficiente durante a vinificação (SU; SILVA, 2006). Esses resíduos tornam-se valiosos para a extração de polifenóis. Os subprodutos obtidos após a vinificação constituem uma fonte muito barata para a extração de flavonoides antioxidantes, podendo ser utilizados como suplementos alimentares, ou na produção de fitoquímicos (GONZÁLEZ-PARAMAS et al., 2004).

A crescente demanda por alimentos seguros que tragam algum benefício à saúde vem sendo fortemente acompanhada pela busca por processos limpos de produção, uma vez que o tratamento de resíduos sólidos e líquidos acarretam custos cada vez maiores para a indústria de alimentos (PIOVESANA et al., 2013).

O trabalho teve como objetivo a caracterização físico-química, a determinação da atividade antioxidante, antocianinas e polifenóis do bagaço de mirtilo proveniente da produção de bebidas fermentadas e da farinha obtida do bagaço, bem como as propriedades funcionais tecnológicas e a estabilidade microbiológica destas farinhas.

\section{MATERIAL E MÉTODOS}

\section{Amostras}

Os mirtilos das cultivares Bluegem, Flórida M e Clímax, foram adquiridos na cidade de Caxias do Sul-RS, Brasil. Foram levados ao laboratório de Bromatologia do Departamento de Tecnologia e Ciência dos Alimentos da UFSM, onde foram selecionados de acordo com o grau de maturação, excluindo-se os frutos muito maduros ou muito verdes. Os frutos foram misturados, e parte foi usada na elaboração de fermentado de mirtilo, de onde foi gerado o bagaço de mirtilo e o restante foi usado para produção de farinha.

A desidratação dos frutos e do bagaço de mirtilo foi realizada em estufa com circulação forçado de ar, à temperatura de $60{ }^{\circ} \mathrm{C}$, por 36 horas. As amostras desidratadas foram trituradas em micromoinho refrigerado a $4^{\circ} \mathrm{C}$, obtendo-se as farinhas de mirtilo e de bagaço de mirtilo. Após a moagem, as farinhas foram acondicionadas em potes plásticos de polipropileno, devidamente etiquetadas e armazenadas em temperatura ambiente de $25{ }^{\circ} \mathrm{C}$.

\section{Preparo dos extratos}

Para a obtenção dos extratos, os frutos, o bagaço e as farinhas foram triturados juntamente com solução extratora acidificada de etanol/ácido clorídrico/água na proporção de 70/1/30 (v/v/v), em homogeneizador do tipo ultraturrax, dimensionado para amostras pequenas, e centrifugados a $5.000 \mathrm{rpm}$, por 15 minutos. O sobrenadante foi separado para as análises de compostos fenólicos, antocianinas e atividade antioxidante.

\section{Composição centesimal}

As determinações de umidade, lipídeos, proteínas, cinzas e carboidratos (por diferença), do mirtilo (M), farinha de mirtilo (FM), bagaço de mirtilo (BM) e farinha de bagaço de mirtilo (FBM) foram realizadas segundo a AOAC (1995). 


\section{Análises físico-químicas}

Os sólidos solúveis totais (SST), expressos em graus Brix, foram determinados por refratometria; a acidez total titulável (ATT), por titulação, com os resultados expressos em percentagem de ácido málico, e o $\mathrm{pH}$, determinado em potenciômetro digital com inserção do eletrodo diretamente na farinha diluída em $100 \mathrm{~mL}$ de água destilada, todas realizadas segundo IAL (1985).

\section{Antocianinas totais}

A determinação de antocianinas totais, segundo Di Stefano et al. (1989), foi realizada pela leitura da absorbância em $533 \mathrm{~nm}$. Todas as amostras (M, BM, FM, FBM) foram diluídas com uma solução de etanol/ácido clorídrico/água na proporção de 70/1/30 (v/v/v). A leitura foi feita em espectrofotômetro, utilizando como branco a água, e os resultados, expressos em mg/100 g de cianidina.

\section{Polifenóis totais}

A concentração de polifenóis foi determinada pelo método colorimétrico descrito por Singleton e Rossi (1965). Os extratos brutos dos frutos e do bagaço foram diluídos na proporção de 1:100, e os extratos das farinhas, na proporção de 1:20. Foram colocados em um tubo de ensaio, $2 \mathrm{~mL}$ de cada amostra diluída, $10 \mathrm{~mL}$ de reagente de Folin Ciocalteau diluído na proporção de 1:10 e $8 \mathrm{~mL}$ de carbonato de sódio $7,5 \%$, onde permaneceram em repouso por $2 \mathrm{~h}$ no escuro. As leituras da absorbância foram feitas em comprimento de onda de $765 \mathrm{~nm}$. Os resultados foram expressos em $\mathrm{mg}$ de equivalente de ácido gálico (EAG) por $100 \mathrm{~g}$ de fruto/farinha.

Atividade antioxidante pelo método de DPPH A avaliação da atividade antioxidante das amostras (M, BM, FM e FBM) seguiu a metodologia de Brand-Williams et al. (1995) com algumas modificações, monitorando-se o consumo do radical DPPH pelas amostras, através da medida do decréscimo da absorbância de soluções de diferentes concentrações $(20 ; 10 ; 5 ; 2,5 ; 1,25 ; 0,6 ; 0,3$ e $0,15 \mathrm{mg}$ / $\mathrm{mL})$. As leituras foram feitas em espectrofotômetro UV-Vis no comprimento de onda $517 \mathrm{~nm}$, após 30 minutos, e convertidas em porcentagem de atividade antioxidante (AA), por meio da seguinte fórmula:

$\mathrm{AA}(\%)=100-\left\{\left[\left(\right.\right.\right.$ Abs.- $\left.\left._{\text {amostra }}-\mathrm{Abs}_{\text {branco }}\right) \times 100\right] /$ Abs.- ${ }_{\text {controle }}$ \}

Os resultados foram expressos em $\mathrm{EC}_{50}$ (concentração de extrato em $\mathrm{mg} / \mathrm{mL}$ capaz de reagir com $50 \%$ do radical presente na solução de DPPH).
Para tanto, quanto menor o valor do $\mathrm{EC}_{50}$, maior é a atividade antioxidante do extrato analisado.

Estabilidade microbiológica

Nas amostras de farinha (FM e FBM), foram realizadas as análises de coliformes totais $\left(\mathrm{a} 35^{\circ} \mathrm{C}\right) \mathrm{e}$ termotolerantes $\left(\mathrm{a} 45^{\circ} \mathrm{C}\right.$ ) bem como a determinação de bolores e leveduras, segundo a APHA (2001). As farinhas foram analisadas no tempo zero e aos 90 dias de armazenamento, em potes de polipropileno, à temperatura ambiente de $25^{\circ} \mathrm{C}$. farinhas

Propriedades funcionais tecnológicas das

Para a avaliação das propriedades funcionais tecnológicas das farinhas, foram realizadas as análises de capacidade de absorção de gordura pelo método de Lin et al. (1974), capacidade de absorção de água, conforme descrito por Sosulski (1962), atividade emulsificante e estabilidade da emulsão pelo método de Dench et al. (1981).

Análise estatística

Os resultados obtidos foram submetidos à análise descritiva.

\section{RESULTADOS E DISCUSSÃO}

O mirtilo pode ser caracterizado como um fruto com elevado conteúdo de água $(73,43 \%)$, assim como o bagaço (70,8\%) (Tabela 1). Os teores de umidade das farinhas estão abaixo de 7\%, encontrando-se de acordo com a RDC no 263, de 22 de setembro de 2005 da ANVISA, que aprova o Regulamento Técnico para produtos de cereais, amidos, farinhas e farelos (máximo de 15\%). O fruto, o bagaço ou as farinhas apresentaram baixa concentração de lipídeos. O fruto apresentou 0,72\%, valor inferior ao relatado pelo banco de dados da USDA (2012), de 2,09\%.

A farinha do bagaço de mirtilo contém aproximadamente três vezes os teores de proteína e cinzas do bagaço fresco. Esta diferença devese à adição e à propagação de leveduras durante a fermentação do mosto de mirtilo. Segundo Asquieri et al. (2004), neste processo, adicionamse aproximadamente $10 \mathrm{~g}$ de levedura de cerveja/L no mosto preparado, o que explica o aumento de proteínas e de resíduos minerais no bagaço fermentado. $\mathrm{O}$ teor de proteína e cinzas do mirtilo foi de $0,80 \%$ e $0,24 \%$, respectivamente, semelhante aos analisados pela USDA (2012), que foram de $0,74 \%$ e $0,24 \%$.

$\mathrm{O}$ teor de carboidratos totais da farinha de 
mirtilo (86,78\%) foi elevado. O fruto e o bagaço de mirtilo também apresentaram valores superiores de carboidratos, $24,79 \%$ e $25,86 \%$, respectivamente, em comparação aos descritos pela USDA (2012), que reportaram valores de $14,49 \%$ para o mirtilo.

$\mathrm{O} \mathrm{pH}$ encontrado para os frutos e farinhas (Tabela 2) foi baixo $(3,3)$, sendo um fator importante para a conservação das farinhas e, portanto, limitante na capacidade de desenvolvimento de microrganismos deteriorantes, os quais crescem em pHs superiores a 4,5.

Os sólidos solúveis totais (SST) proporcionam a doçura do fruto durante a maturação e é um importante atributo na determinação de seu sabor (JESUS et al., 2004). Para o mirtilo, foram encontradas baixas concentrações de SST, sendo $5,23^{\circ}$ Brix, enquanto Raseira e Antunes (2004) descrevem teores de SST na região de PelotasRS, para a cultivar Bluegem como sendo de 10,5 a $12,8^{\circ}$ Brix. Por outro lado, Braga et al. (2011) encontraram valores de 2,35 a $4,96^{\circ}$ Brix para resíduo de acerola, valores semelhantes aos encontrados para o mirtilo,enquanto para o bagaço de mirtilo foi encontrado um conteúdo de $2,13^{\circ}$ Brix. A farinha de mirtilo obteve $3,60^{\circ}$ Brix. Os diferentes valores encontrados nas diversas pesquisas demonstram que os frutos apresentam diferenças na composição em função de vários fatores, como espécie genética, solo, grau de maturação e outros. A acidez total para a farinha de mirtilo e farinha do bagaço foi de 0,20 a $0,23 \mathrm{~g} / 100 \mathrm{~g}$ em ácido málico. Borges et al. (2009) e Rodrigues et al. (1992) analisaram a acidez de mirtilos e verificaram valores entre 0,06 e $0,14 \mathrm{~g} / 100 \mathrm{~g}$ em ácido málico, portanto menos ácidos que os analisados nesta pesquisa. Os maiores valores de acidez total encontrados eram esperados, uma vez que as quantidades de SST nos frutos de mirtilo eram muito baixas. Durante a maturação das frutas, uma das principais modificações em suas características é o acúmulo de açúcares, que ocorre simultaneamente com a redução da acidez. A cor é um importante parâmetro de qualidade, relacionada com o teor em antocianinas, com maior presença na casca do fruto de mirtilo. A concentração de antocianinas encontrada no mirtilo, $61,67 \mathrm{mg} / 100 \mathrm{~g}$, foi superior ao das polpas de amora, uva, morango, açaí, acerola e goiaba, que foram de 41,8; 30,9; 23,$7 ; 22,8 ; 16,0$ e $2,7 \mathrm{mg} / 100 \mathrm{~g}$ peso da matéria fresca, respectivamente, encontrados por Kuskoski et al. (2006). A concentração de antocianinas para o bagaço foi um pouco inferior, $57,32 \mathrm{mg} / 100 \mathrm{~g}$, mas dentro dos valores encontrados por Soares et al. (2008), entre 7,02 e $82,15 \mathrm{mg} / 100 \mathrm{~g}$ de peso fresco em extrato de bagaço de uva Isabel e Niágara, resultados coerentes por se tratarem de resíduos de fermentação. Dados da literatura comprovam que o processo de vinificação reduz significativamente os teores de antocianinas bem como o teor de polifenóis totais nos subprodutos, afetando com isso a cor deste subproduto (SU; SILVA, 2006). A maior concentração de antocianinas foi encontrada para as farinhas de mirtilo e bagaço, 124,5 e $115,21 \mathrm{mg} / 100$ $\mathrm{g}$, respectivamente, mas abaixo do verificado por Rockenbach et al. (2007) para o extrato de farinha do bagaço de uva Vitis vinífera, que variou de 130 $\mathrm{mg} / 100 \mathrm{~g}$ a $1.930 \mathrm{mg} / 100 \mathrm{~g}$. As farinhas apresentaram alta concentração de polifenóis, 624,68 e 460,35 mg de $\mathrm{EAG} / 100 \mathrm{~g}$, respectivamente, na farinha do mirtilo e na do bagaço. No bagaço, a extração de polifenóis foi menor, pois como é um resíduo proveniente da fermentação, os compostos fenólicos são removidos para a bebida, restando menor quantidade no bagaço (ISHIMOTO, 2008). Cataneo et al. (2008) estudaram o bagaço de uva, do processamento de vinho, e obtiveram concentração inferior de polifenóis (161,67 $\mathrm{mg}$ de EAG/100 g de bagaço).

A concentração de polifenóis encontrada no mirtilo foi de 431,43 mg de EAG/100 g de fruto. Silveira et al. (2007) encontraram 277,40 mg de $\mathrm{EAG} / 100 \mathrm{~g}$ de fruto de polifenóis para mirtilos. Boari Lima et al. (2008) observaram valores de polifenóis de 450 e $490 \mathrm{mg} / 100 \mathrm{~g}$ de frutos ao estudar as variedades de polpa de jabuticaba Paulista e Sabará, verificando valor superior ao encontrado neste estudo. Segundo Zadernowski et al. (2005), a concentração de polifenóis depende das diferenças genéticas existentes entre as várias cultivares, das condições de solo e clima do local de cultivo, das técnicas utilizadas em sua produção, bem como do grau de maturação do fruto.

A atividade antioxidante variou entre as amostras, apresentando um comportamento semelhante ao observado nas outras variáveis, demonstrando haver uma correlação com os teores de compostos fenólicos e antocianinas. As amostras com maior capacidade de sequestro do radical DPPH foram a farinha do mirtilo e o extrato de mirtilo, com $\mathrm{EC}_{50}$ variando de 2,77 a $3,83 \mathrm{mg} / \mathrm{mL}$, respectivamente, valores semelhantes ao encontrado para a farinha do bagaço de mirtilo, que foi de $\mathrm{EC}_{50}$ $3,90 \mathrm{mg} / \mathrm{mL}$ neste experimento. Luzia e Jorge (2009) encontraram para o extrato de jambolão $\mathrm{EC}_{50} 0,12$ $\mathrm{mg} / \mathrm{mL}$. Vieira et al. (2011) estudaram a polpa de bacuri e verificaram $\mathrm{EC}_{50} 2,36 \mathrm{mg} / \mathrm{mL}$. A menor atividade antioxidante foi exibida pelo bagaço, que apresentou maior $\mathrm{EC}_{50}(5,61 \mathrm{mg} / \mathrm{mL})$, pois o mesmo apresenta menor teor de fenólicos, os quais foram transferidos para o fermentado. 
$\mathrm{Na}$ Tabela 3, encontram-se os resultados referentes à estabilidade microbiológica das farinhas obtidas do fruto e do bagaço do mirtilo. Não foram constatados coliformes a $35 \mathrm{C}$, e coliformes a 45 $\mathrm{C}$ nas farinhas. A ausência desses microrganismos é um indicativo da qualidade higiênico-sanitária, bem como da eficiência no controle da contaminação durante todas as etapas do processamento. Os valores para bolores e leveduras são baixos, de acordo com a Resolução - RDC n ${ }^{\circ} 12$, de 12 de janeiro de 2001 (ANVISA, 2001). Análises obtidas para a farinha de banana verde também demonstraram resultados semelhantes (BORGES et al., 2009). Portanto, durante o período de armazenamento (90 dias), as farinhas permaneceram inalteradas do ponto de vista microbiológico.

As propriedades funcionais tecnológicas das farinhas do mirtilo e do bagaço estão representadas na Tabela 4. Observa-se que ambas as farinhas apresentaram alta capacidade de absorção de gordura (300\%), valores superiores aos encontrados para as farinhas de mamão, abóbora e amendoim, cujos valores foram 247,61\%, 180,28\% e 205\%, respectivamente (BEAUCHAT et al., 1975; PORTE et al., 2011). Em função dos valores obtidos, estas farinhas podem ser utilizadas como ingredientes em produtos viscosos, como sopas, massas e extensores de carne. Segundo Kinsella (1976), altos valores de absorção de gordura são desejáveis para melhorar a sensação dos produtos na boca. Em contrapartida, as farinhas analisadas apresentaram baixa atividade emulsificante e estabilidade da emulsão semelhante aos valores encontrados por Porte et al. (2011) em farinhas de mamão e abóbora, com valores de 48, 14 e 48,06\%, respectivamente, demonstrando que tais farinhas não são indicadas para uso em sistemas de emulsão. Por outro lado, as farinhas de mirtilo e de bagaço de mirtilo estudadas apresentaram altos valores de absorção de água (800 e 1.000\%, respectivamente). Sangronis et al. (2004) e Porte et al. (2011), estudando as propriedades das farinhas de feijão, mamão e abóbora, encontraram valores inferiores a este trabalho, ou seja, de 150 a 270,5\% para feijão, 640,88\% para mamão e 446,80\% para a farinha de abóbora. A propriedade de absorção de água é bastante importante em produtos cárneos, bolos e pães, o que permite concluir com esses resultados que a utilização das farinhas de mirtilo e bagaço de mirtilo, nestes produtos alimentares,podem ser desejáveis.

TABELA 1 - Composição centesimal do fruto, bagaço, farinha do mirtilo e farinha do bagaço de mirtilo.

\begin{tabular}{c|c|c|c|c|c}
\hline \multirow{2}{*}{ Tratamento } & $\begin{array}{c}\text { Umidade } \\
(\%)\end{array}$ & $\begin{array}{c}\text { Proteína } \\
(\%)\end{array}$ & $\begin{array}{c}\text { Cinzas } \\
(\%)\end{array}$ & $\begin{array}{c}\text { Extrato Etéreo } \\
(\%)\end{array}$ & $\begin{array}{c}\text { Carboidratos } \\
(\%)\end{array}$ \\
\hline M & $73,43 \pm 0,02$ & $0,80 \pm 0,02$ & $0,24 \pm 0,01$ & $0,72 \pm 0,07$ & $24,79 \pm 0,06$ \\
BM & $70,80 \pm 0,60$ & $1,57 \pm 0,04$ & $0,30 \pm 0,02$ & $1,46 \pm 0,27$ & $25,86 \pm 0,32$ \\
FM & $6,78 \pm 0,06$ & $2,81 \pm 0,08$ & $0,87 \pm 0,03$ & $2,74 \pm 0,29$ & $86,78 \pm 0,24$ \\
FBM & $3,47 \pm 0,39$ & $5,27 \pm 0,12$ & $1,02 \pm 0,06$ & $4,52 \pm 0,02$ & $85,15 \pm 0,57$ \\
\hline
\end{tabular}

M: mirtilo; BM: bagaço do mirtilo; FM: farinha de mirtilo; FBM: farinha de bagaço do mirtilo. Médias e desvio-padrão de três repetições.

TABELA 2 - Características físico-químicas do fruto, bagaço, farinha do mirtilo e farinha do bagaço de mirtilo.

\begin{tabular}{ccccc}
\hline Características & $\mathrm{M}$ & $\mathrm{BM}$ & $\mathrm{FM}$ & $\mathrm{FBM}$ \\
\hline $\mathrm{pH}$ & $3,30 \pm 0,05$ & $3,16 \pm 0,12$ & $3,25 \pm 0,03$ & $3,18 \pm 0,07$ \\
$\begin{array}{c}\text { Sólidos Solúveis Totais } \\
\quad\left({ }^{\circ} \text { Brix }\right)\end{array}$ & $5,23 \pm 0,05$ & $2,13 \pm 0,15$ & $3,60 \pm 0,01$ & $0,60 \pm 0,17$ \\
$\begin{array}{c}\text { Acidez Total } \\
(\mathrm{g} \% \text { em ácido málico) }\end{array}$ & $0,21 \pm 0,01$ & $0,24 \pm 0,01$ & $0,20 \pm 0,01$ & $0,23 \pm 0,01$ \\
$\begin{array}{c}\text { Antocianinas } \\
(\mathrm{mg} / 100 \mathrm{~g})\end{array}$ & $61,67 \pm 1,36$ & $57,32 \pm 1,35$ & $124,51 \pm 1,98$ & $115,21 \pm 4,23$ \\
$\begin{array}{c}\text { Polifenóis } \\
(\mathrm{mg} \text { EAG/100g) }\end{array}$ & $431,43 \pm 6,29$ & $297,20 \pm 8,82$ & $624,68 \pm 2,94$ & $460,35 \pm 1,74$ \\
$\begin{array}{c}\text { Atividade Antioxidante } \\
\left(\mathrm{EC}_{50} \mathrm{mg} / \mathrm{mL}\right)\end{array}$ & $3,83 \pm 0,04$ & $5,61 \pm 0,06$ & $2,77 \pm 0,07$ & $3,9 \pm 0,06$ \\
\hline
\end{tabular}

M: mirtilo; BM: bagaço do mirtilo; FM: farinha de mirtilo; FBM: farinha de bagaço do mirtilo. Médias e desvio-padrão de três repetições. 
TABELA 3 - Estabilidade microbiológica das farinhas do mirtilo e do bagaço de mirtilo no tempo inicial e tempo final (90 dias).

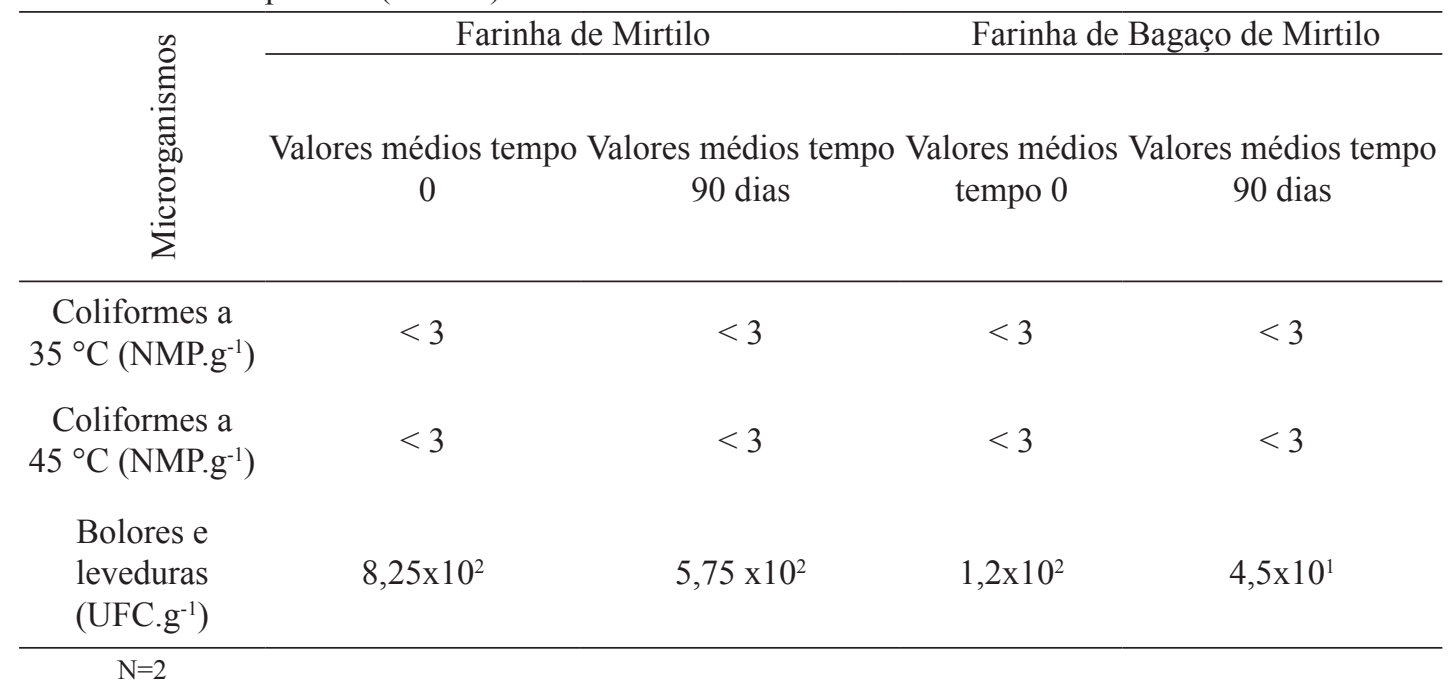

TABELA 4 - Médias dos valores obtidos para as análises de Capacidade de Absorção de Gordura (AG), Capacidade de Absorção de Água (AA), Atividade Emulsificante (AE) e Estabilidade da Emulsão (EE), das farinhas de mirtilo e de bagaço do mirtilo em base seca.

\begin{tabular}{|c|c|c|c|c|}
\hline Tratamento & $\mathrm{AG}(\%)$ & $\mathrm{AA}(\%)$ & $\mathrm{AE}(\%)$ & $\mathrm{EE}(\%)$ \\
\hline Farinha mirtilo & $300 \pm 0,01$ & $800 \pm 0,01$ & $30 \pm 0,02$ & $30 \pm 0,01$ \\
\hline Farinha bagaço de mirtilo & $300 \pm 0,01$ & $1.000 \pm 0,01$ & $30 \pm 0,01$ & $30 \pm 0,02$ \\
\hline
\end{tabular}

\section{CONCLUSÕES}

O mirtilo demonstrou altas concentrações de antocianina e polifenóis, comprovando sua atividade antioxidante.

O bagaço do mirtilo, resíduo da fermentação, enquadrou-se com os parâmetros de qualidade analisados, constituindo-se uma fonte de substâncias nutritivas e bioativas.

As farinhas obtidas do mirtilo e do bagaço apresentaram altas concentrações de antocianinas, polifenóis e baixo IC50. Além disso, apresentaram estabilidade microbiológica durante o armazenamento, influenciadas pelo baixo $\mathrm{pH}$ e umidade.

As farinhas do bagaço e do mirtilo apresentaram-se como boa alternativa para uso em produtos alimentícios, evitando desperdícios, minimizando o impacto ambiental gerado pelo processamento, possibilitando o desenvolvimento de novos produtos com propriedades benéficas à saúde.

\section{REFERÊNCIAS}

ANTUNES, L. E. C.; MADAIL, J. C. M. Mirtilo: uma oportunidade de negócios. 2007. Disponível em: <http://www.todafruta.com.br/todafruta/ mostra_conteudo.asp? conteudo $=15206>$. Acesso em: 27 maio 2013.

ANVISA. Agência Nacional De Vigilância Sanitária. Resolução RDC $n^{\circ} 12$, de 2 jan. de 2001. Dispõe sobre o regulamento técnico sobre padrões microbiológicos para alimentos. Brasília, 2001.

AOAC - Association Official Analytical Chemists. Official methods of analysis of the association of official analytical chemistry. $16^{\text {th }}$ ed. Washington, 1995. p.1141.

APHA - American Public Health Association. Compendium of methods for the microbiological examination of foods. Washington, 2001. p.676. 
ASQUIERI, E. R. et al. Fabricación de vino blanco y tinto de jabuticaba (Myrciaria jaboticaba Berg) utilizando la pulpa y la cáscara respectivamente. Alimentaria, Madrid, v. 355, p. 97-109, 2004.

BEAUCHAT, L. R.; CHERRY, J. P.; QUINN, M. R. Physicochemical properties of peanut flour as affected by proteolysis. Journal of Agricultural and Food Chemistry, Easton, v.23, n.4, p.616-620, 1975.

BOARI LIMA, A. J. et al. Caracterização química do fruto de jabuticaba (Myrciaria cauliflora Berg) e de suas frações. Archivos Latino Americanos de Nutricion, Caracas, v.58, n.4, p.416-421, 2008.

BORGES, A. M.; PEREIRA, J.; LUCENA, E. M. P. Green banana flour characterization. Ciência e Tecnologia de Alimentos, Campinas, v.29, n.2, p.333-339, 2009.

BRAGA, A. C. D. et al. Caracterização e obtenção de farinha do resíduo gerado no processo industrial de clarificação do suco de acerola. Revista Semiárido de Visu, Petrolina, v.1, n.2, p.126-133, 2011.

BRAND-WILLIAMS, W.; CUVELIER, M. E.; BERSET, C. Use of a free radical method to evaluate antioxidant activity. Lebensmittel - Wissenschaft und Technologie, London, v.28, n.1, p. 25-30, 1995.

CATANEO, C. B. et al. Atividade antioxidante e conteúdo fenólico do resíduo agroindustrial da produção de vinho. Semina: Ciências Agrárias, Londrina, v. 29, n.1, p. 93-102, 2008.

DENCH, J. E.; RIVAS, R. N.; CAYGILL, J. C. Selected functional properties of sesame (Sesamum indicum L.) flour and two protein isolates. Journal of the Science of Food and Agriculture, London, v.32, n.6, p.557-564, 1981.

DI STEFANO, R.; CRAVERO, M. C.; GENTILINI, N. Metodi per ló Studio dei polifenoli dei vini. L'Enotecnico, Milano, v.25, n.5, p.83-89, 1989.

GONZÁLEZ-PARAMAS, A. M. et al. Flavanol content and antioxidant activity in winery by products. Journal of Agricultural and Food Chemistry, Easton, v.52, p.234-238, 2004.

IAL - Instituto Adolfo Lutz. Normas analíticas do Instituto Adolfo Lutz: métodos químicos e físicos para análises de alimentos. 3.ed. São Paulo, 1985. v. $1,533 \mathrm{p}$.
ISHIMOTO, E. Y. Efeito hipolipemiante de subprodutos da uva em hamsters. 2008. $196 \mathrm{f}$. (Tese de Doutorado) - Faculdade de Saúde Pública, Universidade de São Paulo, São Paulo, 2008.

JESUS, S. C. et al. Caracterização física e química de frutos de diferentes genótipos de bananeira. Bragantia, Campinas, v. 63, n. 3, p. 315-323, 2004.

KINSELLA, J. E. Functional properties of proteins in foods: a survey. Critical Reviews in Food Science and Nutrition, Cleveland, v.7, n.3, p.219-280, 1976.

KUSKOSKI, E. A. et al. Frutos tropicais silvestres e polpas de frutas congeladas: atividade antioxidante, polifenóis e antocianinas. Ciência Rural, Santa Maria, v.36, n.4, p.1283-1287, 2006.

LIN, M. J. Y.; HUMBERT, E. S.; SOSULSKI, F.W. Certain functional properties of sunflower meal products. Journal of Food Science, Chicago, v.39, n.2, p.368-370, 1974.

LUZIA, D. M. M.; JORGE, N. Composição centesimal, potencial antioxidante e perfil dos ácidos graxos de sementes de jambolão (Syzygium cumini L.). Revista Ciência Agronômica, Fortaleza, v. 40, n. 2, p. 219-223, 2009.

OLIVEIRA, D. A. G. Avaliação química, nutricional e sensorial de uma mistura à base de farinhas de arroz, banana e mandioca, enriquecida com outras fontes proteicas. 1997. 79 f. Dissertação (Mestrado em Agronomia) - Escola Superior de Agricultura "Luiz de Queiroz”, Universidade de São Paulo, Piracicaba, 1997.

PANTELIDIS, G. E. et al. Antioxidant capacity, phenol, anthocyanin and ascorbic acid contents in raspberries, blackberries, red currants, gooseberries and Cornelian cherries. Food Chemistry, Washington, v.102, p.777-783, 2007.

PIOVESANA, A.; BUENO, M.; KLAJN, V. Elaboração e aceitabilidade de biscoitos enriquecidos com aveia e bagaço de uva. Brazilian Journal of Food Technology. Campinas, v.16, n.1, p. 68-72, 2013.

PORTE, A. et al. Propriedades funcionais tecnológicas das farinhas de sementes de mamão e de abóboras. Revista Brasileira de Produtos Agroindustriais, Campina Grande, v.13, n.1, p.91-96, 2011. 
RASEIRA, M. C.; ANTUNES, L. E. Aspectos técnicos da cultura da amora-preta. Pelotas: Embrapa Clima Temperado, 2004. p.54.

ROCKENBACH, I. I. et al. Atividade antioxidante de extratos de bagaço de uva das variedades Regente e Pinot Noir (Vitis vinifera). Revista do Instituto Adolfo Lutz, São Paulo, v. 2, v.66, p. 158-163, 2007.

RODRIGUES, R. M. A. et al. Estudio de la composición quimica de pequeños frutos, arandano, framboesa, groselha blanca, grosella negra, grosella roja y zarzamora producidos en Galicia. Industria Conserve, Parma, v.67, p. 29-33, 1992.

SANGRONIS, E.; MACHADO, C.; CAVA, R. Propriedades funcionales de lãs harinas de leguminosas (Phaseolys vulgaris y Cajan) germinadas. Interciência, Caracas, v.29, n.2, p.8085, 2004.

SILVEIRA, N. G. A.; VARGAS, P. N.; ROSA, C. S. Blueberry's (Highbush group) polyphenols content and chemical composition. Alimentos e Nutrição, Marília, v.18, n.4, p. 365-370, 2007.

SINGLETON, V. L.; ROSSI, J. A. Colorimetry of total phenolics with phosphomolybdic-phosphotungstic acid reagents. American Journal of Enology and Viticulture, Davis, v.16, n.3, p.144-158, 1965.

SOARES, M. et al. Compostos fenólicos e atividade antioxidante da casca de uvas Niágara e Isabel. Revista Brasileira de Fruticultura, Jaboticabal, v.30, n.1, p. 59-64, 2008.
SOSULSKI, F. N. The centrifuge method for determining flour absortion in hard red spring wheats. Cereal Chemistry, Saint Paul, v.39, n.4, p.344-350, 1962.

SOUSA, J. S. I.; PEIXOTO, A. M.; TOLEDO, F. F. Enciclopédia agrícola brasileira. Piracicaba: Edusp, 1995. p.508.

SU, M.; SILVA, J. L. Antioxidant activity, anthocyanins, and phenolics of rabbiteye blueberry (Vaccinium ashei) by-products as affected by fermentation Food Chemistry, London, v.97, n.3, p.447-451, 2006.

USDA. U.S. Department of Agriculture, Agricultural Research Service. National nutrient database for standard reference, release 25. 2012. Disponível em: <http://www.ars.usda.gov/ba/bhmsorc/ndl $>$. Acesso em: 10 maio 2013.

VIEIRA, L. M. et al. Fenólicos totais e capacidade antioxidante in vitro de polpas de frutos tropicais. Revista Brasileira de Fruticultura, Jaboticabal, v.33, n.3, p 888-897, 2011.

WANG, S.Y.; JIAO, H. Antioxidant activity in fruits and leaves of blackberry, raspberry and strawberry varies with cultivar and developmental stage. Journal of Agricultural and Food Chemistry, Easton, v.48, p.140-146, 2000.

Z A D ERNOW S K I, R.; NACZK, M.; NESTEROWICZ, J. Phenolic acid profiles in some small berries. Journal of Agricultural and Food Chemistry, Easton, v.53, p.2118-2124, 2005. 